\title{
Participação de famíllas no Grupo Multifamiliar de Adolescentes Ofensores SeXuais: vergonha e CONFIANÇA
}

\author{
Liana Fortunato Costa*
}

\section{RESUMo}

Trata-se de uma pesquisa qualitativa a respeito da participação de famílias em um Grupo Multifamiliar (GM) com adolescentes ofensores sexuais. A eficácia do GM é reconhecida, pois diminui os índices de reencarceramento e de recidiva de atos infratores. Foram avaliadas sete famílias do GM, através de uma entrevista realizada com as mães ao final da última sessão do GM. A análise de conteúdo das entrevistas configurou três zonas de sentido: (1) a experiência de participar do GM; (2) enfrentamento do tema da violência sexual; (3) as mudanças ocorridas nas interaçôes familiares. A partir desta análise, observamos a ocorrência de mudanças nas relações familiares, apesar da dificuldade e do sofrimento em discutirem esta temática. Por fim, foi verificado que a intervenção em grupo contempla a dimensão do sofrimento de todos. Além disso, favorece a aproximação afetiva, ameniza o contexto de punição ao adolescente, a vergonha e o isolamento da família e do adolescente em relação à comunidade e à família extensa.

Palavras-chave: família; avaliação familiar; grupo multifamiliar; adolescente ofensor sexual.

\section{Abstract}

Participation of families in a Multifamiliar Group of Sexual Offender Adolescents: SHAME AND CONFIDENCE

This text deals with a qualitative research about the participation of families in a Multifamiliar Group (MG) with sexual offender adolescents. Various studies recognize the efficacy

* Psicóloga; Terapeuta Conjugal e Familiar; Psicodramatista; Doutora em Psicologia Clínica pela Universidade de São Paulo; Docente Permanente do Programa de Pós-graduação em Psicologia Clínica e Cultura - PSICC/PCL/IP/UnB. 
of this type of intervention because they decrease the reimprisonment and reincidence indices of infringing acts. Seven families participated in the $M G$; the mothers replied to the instrument at the end of the last session of the $M G$. The analysis of contents gave evidence of three sense zones: (1) the experience of participating in the MG; (2)facing the theme of sexual violence; (3) changes occurred in the familiar interactions. We observed the occurrence of changes in the familiar relations, the difficulty and suffering in discussing this matter. The group intervention contemplates the dimension of suffering of all, favours affection among persons, softens the context of punishment of the adolescent, the shame and isolation of the family and the adolescent.

Keywords: family; familiar evaluation; multifamiliar group; sexual offender adolescent.

\section{INTRODUÇÃo}

Este trabalho é oriundo de uma pesquisa qualitativa sobre a participação de famílias em um Grupo Multifamiliar (GM) com adolescentes ofensores sexuais. Este grupo ocorreu em um ambulatório público de saúde mental infanto-juvenil. O objetivo do trabalho foi conhecer como as famílias percebem o atendimento grupal com foco na violência sexual após o término do grupo. Além disso, consideramos importante saber como esta intervenção, adaptada para a presença de adolescentes ofensores sexuais, pode contribuir para as relaçôes familiares e para o resgate da dimensão de proteção no que diz respeito a crianças e adolescentes envolvidos. $\mathrm{O}$ instrumento utilizado foi uma entrevista realizada com as mães ao final do GM.

\section{O Grupo Multifamiliar com adolescentes ofensores SEXUAIS}

Os Grupos Multifamiliares (GM) foram conhecidos, inicialmente, pela denominação de Terapia Familiar Múltipla, que consistiu em uma adaptação da técnica de grupo ao tratamento de famílias, no início na década de 50, com famílias de pacientes psicóticos (Laquer, 1983). Esta abordagem terapêutica evidencia que as famílias se sentem mais à vontade reunidas quando há maior focalização em suas interações. No caso do GM para adolescentes agressores sexuais, o critério de seleção das famílias é por semelhança de problemática. As mudanças se dão por semelhança, ou seja, quando as famílias presenciam em outras seus conflitos, e, também, por identificação, quando pais e mães aprendem novas soluções com o grupo.

Psic. Clin., Rio de Janeiro, vol.23, N.I, P.I85-20I, $201 \mathrm{I}$ 
É interessante ressaltar que o Grupo Multifamiliar fundamenta-se nos seguintes aportes teóricos: a) Psicologia Comunitária - visando ao trabalho em equipe com diferentes saberes, científicos e populares (Santos, 1999); b) Psicologia Social Crítica e Histórica (Lane \& Sawaia, 1995) - percebendo o ser humano constituído e constituinte do seu meio; c) Terapia Familiar - a família é vista enquanto sistema e a relação é o ponto crucial do trabalho, antepondo-se o interpsíquico ao intrapsíquico; além de utilizar os recursos sistêmicos, como a circularização e a provocação (Minuchin, Colapinto, \& Minuchin, 1999); d) Sociodrama - em que o grupo é o protagonista e as famílias possuem objetivos comuns, além de se identificarem mutuamente (Moreno, 1993); e) Teoria das Redes Sociais - enfoca a interação humana com a troca de experiências, desenvolvendo-se a capacidade autorreflexiva e autocrítica (Sluzki, 1996). Esta intervenção já foi descrita em maiores detalhes em Costa, Penso e Almeida (2005).

Quanto aos grupos específicos para agressores sexuais, outras sistematizações desta abordagem podem ser vistas em Almeida, Penso e Costa (2009); Costa, Penso, Almeida e Ribeiro (2008); Costa, Almeida, Ribeiro e Penso (2009); Costa, Penso, Almeida, Ribeiro e Nogueira (2010). Estes autores adaptaram a abordagem grupal, enquanto intervenção psicossocial, reunindo famílias numa modalidade de atendimento "sob obrigação", a partir de encaminhamento da Justiça. O Grupo Multifamiliar para adolescentes ofensores sexuais constitui-se em uma nova adaptação.

Cada sessão do GM é planejada numa perspectiva voltada para a intervenção dirigida a grupos, com ênfase nas relações sociais. A organização da reunião segue orientação metodológica da sessão psicodramática (Gonçalves, Wolff, \& Almeida, 1988), que indica três etapas: aquecimento, dramatização e compartilhar. A adaptação dessa organização resulta em outras etapas: aquecimento, discussão e conclusão. $\mathrm{O}$ aquecimento tem por objetivo integrar o grupo e estimular a tarefa. A discussão visa aprofundar o tema, desenvolver a capacidade de reflexão sobre o assunto e acolher o sofrimento psicológico advindo das identificações com o tema. A conclusão sintetiza as opiniões sobre o tema discutido, avalia a aprendizagem sobre o tema e formula sugestões práticas às famílias.

As famílias encaminhadas para atendimento no GM têm conhecimento de que farão parte de uma intervenção que visa reflexão sobre a violência intrafamiliar, portanto achamos pertinente apresentar os temas que serão aprofundados nos encontros. O GM para adolescentes agressores sexuais ocorreu em cinco encontros em que foram desenvolvidos os seguintes temas: Proteção: "Eu devo proteger outras crianças mas ainda preciso de proteção"; Sexualidade: "É tempo da sexualidade desabrochar"; Abuso sexual é um crime: "O abuso sexual é um crime e uma violência"; Transgeracionalidade: "Precisamos conhecer nossos antepassados" e Projeto 
de namoro: "Ainda quero namorar muito". Os adolescentes participantes e suas famílias tiveram como critério de inclusão no grupo: sexo masculino; faixa etária entre 12 a 18 anos; ser cliente do ambulatório ou ser encaminhado por qualquer entidade pertencente à Rede de Proteção da Criança ou do Adolescente; estar com os vínculos familiares preservados; ter denúncia de envolvimento em situações de violência sexual contra crianças; estar ou não em cumprimento de medida socioeducativa (Liberdade Assistida - LA, Prestação de Serviço Comunitário - PSC ou Semiliberdade).

\section{Avaliação de intervençốes familiares grupais}

Não nos foi possível conhecer avaliações específicas sobre a efetividade de GMs com esta população (ofensores sexuais) pela inexistência de literatura com este perfil. No entanto, podemos conhecer avaliaçōes de uma intervenção semelhante que se denomina Terapia Multissistêmica (TM). A Terapia Multissistêmica é uma modalidade de atendimento familiar e comunitário que tem suas raízes teóricas e metodológicas em Minuchin (1982). Ela se apresenta como uma válida opção para atendimento a adolescentes com envolvimento com a Justiça e, em especial, nas situações de violência sexual (Henggeler, Melton, \& Smith, 1992). A TM baseiase na avaliação dos recursos e das vulnerabilidades das famílias, envolve todos os membros delas e mais os recursos da comunidade (como as lideranças comunitárias, as figuras de autoridade, o grupo de pares do adolescente). São formadas equipes terapêuticas que trabalham com as famílias por 3 a 5 meses, com ações que somam intervençôes clínicas a açôes provenientes destes outros recursos da comunidade.

A TM, tanto quanto o GM, entende que o adolescente infrator encontra-se em uma fase de transição de seu desenvolvimento. Por isso mantém uma relação de dependência importante com a família e com os aspectos socioculturais e comunitários que o cercam. Um dos aspectos comunitários essenciais para a compreensão desse adolescente é o pertencimento ao grupo de pares, que tem influência sobremaneira em sua conduta. Tanto o estudo de Henggeler et al. (1992) como o estudo de Timmons-Mitchell, Bender, Kishna e Mitchell (2006) reconhecem a eficácia das intervenções que consideram o adolescente em família, porque diminui os índices de reencarceramento e de recidiva de atos infratores. Além disso, estes autores reconhecem que os adolescentes estão ainda muito intimamente ligados às famílias e que os atos violentos têm grande dimensão transgeracional. Isto mostra mais uma razão para não se pensar em intervenções com estes sujeitos sem considerá-los em família. 
O GM, por sua descrição, reúne muitos elementos conceituais em comum com a TM, tais como: toda a família é convidada a participar; a rede social de apoio do adolescente e da família é esperada e valorizada como recurso terapêutico nas sessões; o período de atendimento cobre 3 meses e alcança cerca de 15 horas de intervenção; baseia-se nos aportes teóricos da Terapia Familiar, com a utilização de técnicas características desta modalidade terapêutica. Nossa opção teórica e metodológica é o GM, mas as considerações sobre a TM são relevantes, pois se trata de outra modalidade de intervenção para adolescentes ofensores sexuais, que está sendo amplamente adotada nos Estados Unidos e Canadá (Borduin, Scheffer, \& Heiblum, 2009; Henggeler et al., 1992; Henggeler et al., 2009; Timmons-Mitchell et al., 2006) e que parte do princípio da família e da comunidade como mediadores e potencializadores de mudanças positivas para os atos infratores do adolescente. Sendo assim, possui muitos elementos em comum com a GM.

Além disso, também foi encontrado um estudo de Costa et al. (2009) no qual foi realizada uma avaliação com participantes de um GM de crianças e adolescentes vítimas (não ofensores). Apesar de este estudo não tratar de agressores sexuais, mas sim de vitimas, foram encontradas declaraçôes relevantes de que as relações grupais que reúnem pessoas com vivências e sentimentos semelhantes entre si, ou que se constituem a partir de juntar famílias de igual perfil socioeconômico e cultural e com problemas similares, são vistas como vantagens para o desenvolvimento do trabalho. Outros aspectos apontados foram o recebimento de uma orientação específica, que é dada por um profissional especialista no assunto; o fato de todos poderem discutir a questão da autoridade em relação aos filhos; as mudanças surgidas no âmbito dos relacionamentos por meio de maior contato físico e afetivo com os filhos.

Desta forma, apesar de poucas evidências quanto à avaliação da efetividade da GM com ofensores sexuais, é possível inferir sua efetividade a partir dos dados apontados acima.

\section{MÉTODo}

\section{CONTEXTO}

A pesquisa foi realizada em um ambulatório público de saúde mental, Centro de Orientação Médico Psico-pedagógico - COMPP, unidade de Saúde Mental Infanto-juvenil que compõe a Rede de Proteção a Crianças e Adolescentes no que diz respeito ao atendimento às vítimas e vitimizadores sexuais no Distrito Federal. O GM teve a duração de agosto a dezembro de 2009, nas seguintes etapas: agosto 
- treinamento da equipe e entrevistas com as famílias inscritas no GM; de agosto a dezembro - atendimento e supervisão dos GM com intervalos quinzenais e intercalados com atendimento/supervisão.

\section{SuJEITOS}

Os respondentes foram as 7 mães das famílias participantes do GM, conforme informaçóes no quadro 1 em anexo.

\section{INSTRUMENTO}

O instrumento foi uma entrevista semiestruturada. As perguntas foram realizadas pelos membros da equipe do GM. Os itens constantes deste questionário foram: a) Qual a avaliação que vocês fazem do trabalho do GMF? b) O que a família acha do trabalho em grupo para se discutir o tema da violência? Houve algum momento em que seria melhor estar sozinho para conversar sobre violência? c) Qual foi o tema trabalhado que mais lhe ajudou? Por quê? d) Você sentiu dificuldade para participar do grupo? Em caso afirmativo, que tipo de dificuldade? e) De toda a experiência vivida no grupo, o que mais the marcou? f) Houve alguma mudança em você e/ou na sua família ao longo das atividades do grupo? Em caso afirmativo, quais foram? g) Quais são os sentimentos presentes em você ao final de todos os encontros?

\section{PROCEDIMENTOS}

Após o término do último encontro do GM, a equipe pediu que as famílias respondessem os questionários. Neste grupo, apenas as mães se dispuseram a responder. Cada mãe teve uma pessoa da equipe assessorando-a nas respostas, porém foram elas que completaram o questionário. Esta atividade teve uma duração de 20 a 30 minutos.

\section{CUIDADOS ÉTICOS}

A pesquisa foi inscrita no Comitê de Ética da Fundação de Ensino e Pesquisa em Ciências da Saúde (FEPECS) da Secretaria de Estado de Saúde do Governo do Distrito Federal (GDF) e aprovada com o parecer no 421/2009. 


\section{ANALISE DAS INFORMAÇÕES}

González Rey (2005) propõe uma perspectiva da análise de conteúdo que contém três aspectos essenciais: (1) o processo de construção e o caráter interpretativo das informações; (2) a ênfase no aspecto relacional entre a subjetividade do pesquisador e a dos entrevistados; (3) bem como a produção do conhecimento propriamente dita. Esta proposta configuracional apoia-se na expressão de indicadores que são fenômenos observados, falas, expressões não verbais e comportamentos que o pesquisador se dirige a partir de significações apreendidas. Os indicadores são construídos durante o próprio processo de investigação e análise, constituindo-se em ferramentas essenciais para a definição das zonas de sentido. As significações em comum dos indicadores oferecem o critério para a construção das zonas de sentido. As zonas de sentido produzem conjuntos de interpretação, que não possuem a pretensão de generalização, mas produzem um conhecimento que é contextual, próprio da experiência aqui relatada.

\section{Discussão dos RESUlTADos}

Após a leitura dos questionários e a pontuação dos indicadores, construímos 3 zonas de sentido que abarcam as avaliações: a) Sobre a experiência de participar do GM, b) Sobre enfrentamento do tema da violência sexual e c) Sobre as mudanças ocorridas nas interaçôes familiares.

a) Sobre a experiência de participar do GM: "A vida é uma rua sem fim para o conhecimento de uma pessoa"

É necessário resgatar o Quadro 1 (em anexo) com informações sobre as famílias. Constatamos que todos os adolescentes cometeram violência sexual intrafamiliar. Isto traz duas questôes de imediato: o GM compreende atendimento a toda a família, desse modo as vítimas estão presentes nas sessões; as famílias comparecem com sentimentos paradoxais em função de que trazem o agressor e a vítima. A primeira questão requer decisão metodológica, a depender se há ou não decisão judicial para que não haja contato da vítima com o agressor. A segunda questão requer manejo para que o GM não se transforme em um tribunal no qual sejam ratificadas as sanções ao adolescente. Esta condição do grupo pode ter duas dimensões que se complementam, mas podem ser vistas como opostas também. Traz dificuldades do ponto de vista metodológico, porém é percebida pelas 
famílias como complicado. Como exemplo disso uma das mães relata o seguinte: "Não gostei de saber que outras famílias sabem que estamos juntas pelo mesmo motivo" (mãe).

A seguir serão apresentadas e discutidas algumas questões relevantes quanto ao grupo a partir das falas das mães.

"Aprendi muito". "Auxilia na relação com os filhos". "Me sinto mais feliz após a tempestade com a ajuda de profissionais". Estas frases são exemplos do saldo positivo que as famílias apontam para a participação no GM. O grupo funciona como apoio, a conversa é boa e a fala dos profissionais tem um valor definido, afinal são especialistas falando para as famílias, conforme pontuam Henggeler et al. (1992) e Timmons-Mitchell et al. (2006).

"Alegria de aprender junto com outras pessoas". "Aprender e tirar dúvidas". Parece que aprender junto e compartilhar são significativos, veem que não estão sós em suas dores. Embora esta condição também seja fonte de dificuldades, eles se queixam de sentir vergonha por todos saberem o motivo do GM. Para receberem apoio terão que avançar além da necessidade de guardarem segredo sobre o que ocorreu com a família. Vergonha e segredo estão intimamente associados nas dificuldades de a família assumir, fora do âmbito doméstico, a verdade dos fatos (Miller, 1994).

"No final, a queixa é de que é pouco". Embora o GM alcance 15 horas de intervenção, há ainda uma queixa de que querem mais. Fazemos uma avaliação da efetividade (Hirsch, 1998) que busca saber se houve mudanças na dimensão de proteção que a família organiza em torno de seus membros em vulnerabilidade. Quanto a esta queixa, Headman e Cornille (2008) falam da existência de vulnerabilidades maiores nestas famílias, também em função da ausência de demandas por atendimento como hábito de resolução de problemas. Em nossa opinião, as mães que gostariam de mais encontros são as que se sentem inseguras de adotarem novos comportamentos sugeridos ao longo do GM.

"Não senti para vir". "Todos ajudam". "Difícil é convencer os filhos a participar". "Sair do horário do trabalho sem dizer sobre o que vai ser atendido". Outro aspecto difícil é como conciliar o trabalho, a faxina com o horário do GM que, via de regra, acontece durante o dia. Há uma observação de que é difícil convencer os adolescentes a irem ao GM. Nesse ponto, pensamos que o tratamento é sob obrigação. Deve ficar claro que os adolescentes estão cumprindo medida socioeducativa, portanto faz parte do cumprimento da medida a participação no GM. Porém há que se reconhecer que o comparecimento ao GM implica em movimentos diferentes de querer vir e não querer vir. As frases acima mostram essa ambivalência em função de que a violência sexual intrafamiliar será o tema das sessões, e o motivo 
do comparecimento é que houve um abuso sexual na família. As dificuldades de ordem de horário podem se constituir num argumento lógico usado para falar sobre o quanto é difícil admitir o abuso sexual intrafamiliar.

"Me marcou a conversa em particular com a psicóloga". "Parece que nunca mais poderei ter confiança no meu filho". "Foi a brincadeira de gato e rato, todos viram e entenderam do que se tratava de saber proteger". "A conversa sobre o genograma, por causa das perguntas". "A proteção dos pais para os filhos". "Encontrar apoio quando se pensa que tudo está perdido". "dinâmica do gato e rato porque ensinou claramente o que proteger o filho". "quando minha irmã compareceu no grupo e deu uma declaração de valor sobre nós". Os comentários sobre falta de confiança e sobre sua recuperação são muito importantes, pois o prejuízo que a família tem em relação à violência intrafamiliar, e em especial a mãe, é a perda da confiança no adolescente. Este ponto traz muito sofrimento.

Duas mães se referiram com ênfase a uma brincadeira ocorrida durante o GM. Realizamos a brincadeira de gato e rato, na qual uma pessoa no lugar do gato perseguia outra no lugar do rato para comê-lo, e este tinha que se defender. A brincadeira proporcionou uma significação potente sobre o dever de proteger crianças, sobre a vulnerabilidade da criança diante do ofensor e sobre a obrigação de todos estarem atentos a isto. A brincadeira buscou ainda ilustrar, na ação, a relação de dominação e força do mais forte sobre o mais fraco. Costa e Santos (2004) apontam a responsabilidade do contexto jurídico em criar as condições para que a violência seja significada como tal, já que estas famílias têm muitas dificuldades de perceberem e definirem como violência aquelas que ocorrem cotidianamente dentro das famílias e que são encaradas como atos rotineiros. A passagem da família pelo contexto jurídico apresenta uma oportunidade para uma ressignificação da violência como algo banal, para a violência como violência. Pensamos o mesmo dos atendimentos terapêuticos sobre esta temática.

Foi falado ainda que o momento em que se construiu o genograma e se pôde constatar a repetição da violência ou da violência sexual presentes na família foi uma oportunidade privilegiada de tomada de consciência e do dever dos adultos de impedirem que isto volte a acontecer. O genograma é um instrumento utilizado pelos terapeutas de família para apreenderem informações que constroem uma representação dos laços transgeracionais e intergeracionais (McGoldrick \& Gerson, 1995).

Há, ainda, uma fala de uma mãe que ficou extremamente sensibilizada com a participação de sua irmã no GM e com seu testemunho sobre o esforço que esta mãe faz para levar adiante sua família depois do ocorrido. Esta mãe sentiu sua autoestima elevada. Sinclair e Martínez (2006) já chamam atenção para as mudanças 
na autoestima de mães cujos filhos sofreram abuso sexual, considerando-as como vítimas secundárias da violência perpetrada. Entendemos que mais difícil deve ser o fato de que essas mulheres têm sob sua responsabilidade uma criança vitimada e um adolescente vitimizador, além de um contexto no qual não conseguiram impedir a violência.

b) Sobre o enfrentamento do tema da violência sexual: "Eu prefiro conversar sozinha sobre o tema". "Eu prefiro conversar em conjunto com outras pessoas"

O título dessa segunda zona de sentido revela a incongruência entre as famílias que compuseram o GM quanto a ser melhor ou mais difícil conversar sobre a presença do tema violência na família. A seguir serão discutidos os pontos mais relevantes.

"Difícil é contar sobre a violência praticada pelo filho". "Não tem problema discutir violência em conjunto". "Melhor conversar com outros que sozinho". Não há uma grande concordância. As famílias que acham melhor conversar sobre violência com outras famílias acreditam nisso porque percebem essa condição como um momento de receberem apoio, sentem-se aliviadas por saberem que não estão sós em seu sofrimento. Tanto Henggeler et al. (1992) quanto Timmons-Mitchell et al. (2006) concordam com esta posição. Estes autores enfatizam o valor da conversa como uma poderosa alavanca de ajuda, uma situação na qual os iguais se ajudam, o que é um dos critérios da constituição do GM. Logo após a denúncia da violência sofrida, a circunstância exige comportamentos e iniciativas por parte da família que são muito diferentes até o instante anterior à denúncia. A partir daí, a família tem que apresentar comportamentos assertivos e de enfrentamento ao fato. Percebemos, então, que o fato de as famílias poderem falar entre si possui um poder de apoio e reforço para uma série de iniciativas e decisões que esta nova fase da vida exige. É unanimidade entre autores a importância de ajudar a mãe da criança vítima de abuso sexual tanto quanto a própria criança. No caso de violência intrafamiliar, na qual o agressor sexual está presente, estes aspectos tomam uma forma muito complexa (Hooper, 1994; Vizir et al., 2004).

As famílias que disseram achar muito difícil estar em grupo expressam-se assim por vergonha de admitir publicamente que há violência em casa e pela cobrança de que a família não conseguiu evitar isto. Neste grupo havia uma mãe que participou de um outro GM ocorrido em 2007. Nessa ocasião suas três filhas haviam sido abusadas sexualmente pelo pai. Este foi sentenciado a 8 anos de prisão e, em 2009, o filho mais velho de 14 anos abusou sexualmente da irmã de 4 anos. Essa mãe não se cansava de repetir que ela não se conformava de não ter visto nada da primeira e 
nem da segunda vez, colocando sobre si mesma a responsabilidade de tudo. Talvez, por isto, sua fala seja tão enfática: “Dá alívio várias famílias conversando". Ela vê no apoio de várias pessoas conversando uma possibilidade de alívio, já que o grupo, sempre, não assume um discurso acusatório e sim de encorajamento.

"Falar da experiência na delegacia, foi muito difícil". "Mais difícil no início, depois a gente se expressa melhor". Um dado interessante é que, neste grupo, somente haviam sido feitas 4 notificações sobre a violência. É importante informar que, embora esteja apontada no Título II Das Medidas de Proteção do Estatuto da Criança e do Adolescente (ECA) (1990) a obrigação de notificação da existência de violência para a proteção da criança, isso ainda não ocorre de forma oficial na maioria dos casos. Mormente nessas situações de abuso sexual intrafamiliar cometido pelo adolescente, em que duas notificações precisam ser feitas. Uma diz respeito à medida de proteção destinada à criança vitimizada e outra à medida socioeducativa (que também tem um caráter protetivo) destinada ao adolescente agressor. Mesmo nas situações em que a família é encaminhada pelo Conselho Tutelar, o encaminhamento sem denúncia formal pode ocorrer, cabendo, então, à instituição de atendimento as medidas necessárias. Estamos falando aqui de uma realidade que demonstra a precariedade ainda presente da aplicação do ECA e da eficiência dos Conselhos Tutelares.

Por outro lado, as famílias se queixam do momento em que buscam a delegacia para denunciar. A queixa, em geral, é de que os policiais oferecem maus-tratos e acusações de negligência. De maneira geral, percebemos que as famílias com adolescentes ofensores sexuais não buscam espontaneamente nenhum órgão do sistema justiça para denunciar, nem mesmo o Conselho Tutelar. Se houve denúncia, ela foi feita por um parente (quando a criança abusada é um primo, por exemplo), ou quando há desconfiança por parte de um profissional que tenha acesso à criança (professor, por exemplo). Se as estatísticas sobre violência sexual com relação às vítimas não são confiáveis (Gonçalves \& Ferreira, 2002), sobre os ofensores sexuais adolescentes é inexistente. Por vergonha, as famílias preferem silenciar sobre o evento violento e adotar seus próprios procedimentos de investigação, culpabilização e reparação. Vizir et al. (2004) e Sanderson (2005) apontam a vergonha como um fator importante para o fechamento das famílias em si mesmas, o que, desse modo, amplifica os prejuízos de contatos sociais tão necessários à reintegração da criança abusada em sua rede de sociabilidade. Agregamos que esta observação também se faz verdadeira em relação ao adolescente ofensor sexual.

c) Sobre as mudanças ocorridas nas interações familiares: "Tenho mais confiança e convicção, quero participar do momento do namoro dele" 
"Percebo mudanças no filho, está mais responsável”. "Eu mudei”. "Ajudou a família toda. Meu filho está mais participativo". "Mais união e diálogo". "Conversar diferente aceitando as diferenças entre os filhos". As principais mudanças apontadas pelas mães, que foram as respondentes, são quanto à aproximação afetiva na relação com o filho ofensor sexual. Como já vimos, após a descoberta da violência, as famílias, em especial as mães, desenvolvem sentimentos de vergonha pelo ato cometido. A vergonha é um sentimento sempre presente nas famílias que tiveram situação de criança ou adolescente abusado sexualmente. Neste caso temos uma vergonha que é relativa à presença de uma criança abusada e de um adolescente ofensor sexual. O sentimento de vergonha se instala quando a identidade é alterada (Gaulejac, 2006). Para este autor, o sofrimento psíquico advindo da vergonha tem uma faceta individual e outra social. Nessas situaçôes que enfocamos, percebemos que a vergonha toma essas duas dimensões, inclusive estar no GM é desafio para o enfrentamento da vergonha social. "A dignidade é a mobilização do sujeito para resistir ao sofrimento e salvaguardar sua subjetividade" (Gaulejac, 2006: 108). Esta observação dá sentido às falas das mães sobre a importância de se readquirir confiança no filho e, assim, retomar os papéis sociais na comunidade e a sociabilidade da família. Nesta ação de recomposição de papéis, alguns aspectos se evidenciam: a recuperação da relação afetiva com o filho, a retomada do diálogo e união com ele e com os outros membros da família. Muitos são os autores que enfatizam a importância da reformulação familiar no trabalho de restauração da proteção devida às crianças e adolescentes violados (Furniss, 1993; Henggeler et al., 1992; Hooper, 1994; Sanderson, 2005; Timmons-Mitchel et al., 2006; entre outros).

"Ajudou com confiança, parece que nunca mais iria poder confiar no filho". "Me tornei mais flexível com meu filho e decidi reconquistar sua confiança, antes pensava de que deveria ser só punido". "Mais confiança e convicção". Pensamos que ao retomar estes sinais de reaproximação com o adolescente há uma recolocação do mesmo no papel de filho, e desse modo observamos a retomada de uma posição de autoridade. Timmons-Mitchell et al. (2006) colocam que as intervenções familiares, neste contexto, trazem mudanças com relação a este aspecto. Isto é fundamental para o redirecionamento dos interesses do jovem no sentido de afastá-lo de maiores contatos com situações sociais nas quais ele estaria mais vulnerável. Por outro lado, autores da Terapia Familiar, como Minuchin (1982), apontam que o resgate da autoridade familiar é um aspecto fundamental para a funcionalidade dos papéis familiares.

"Ser melhor para os filhos e a família, participar do momento do namoro dos filhos". Esta fala que aponta a disponibilidade da mãe em ver seu filho (adolescente ofensor sexual) namorando é fundamental e carrega o desarmamento da bomba 
familiar, ou seja, a sexualidade do adolescente. Assim como as famílias com crianças violadas sexualmente prendem essas crianças com medo de a violência se repetir (Costa \& Lima, 2010), também as famílias desses adolescentes os encarceram. A prisão domiciliar é vista como prevenção de outras violências. Este aspecto é essencial, pois todos os adolescentes presentes no GM se queixaram de não poderem sair e não terem contato com outras pessoas. Em vista disso, pensar sobre o namoro futuro do adolescente é avançar no questionamento dessa falsa solução. Pensar sobre o namoro do filho contém ainda outra dimensão que é essencial: o diálogo em família sobre sexualidade. Oliver (2007) chama atenção que a retomada do cuidado sobre o adolescente ofensor sexual tem que incluir a educação, a informação e a orientação sobre suas fantasias sexuais. Como estas famílias vão se aproximar dessa condição desejável, se não se pode falar sobre o ocorrido e nem sobre sexualidade? Esse autor recomenda que a família e os profissionais conversem com o adolescente sobre as causas da ofensa sexual, sobre os prejuízos causados às crianças e ofereçam orientação e continência para suas ansiedades sexuais e fantasias típicas da idade. A manutenção permanente de um clima de diálogo e aproximação afetiva com o adolescente é vista como prevenção de novos atos de violência (Oliver, 2007; Timmons-Mitchell et al., 2006).

\section{ConsideraçôES Finais}

As informações dadas pelas mães, em nome da família, mostram, de forma inequívoca, a importância da participação da mãe e dos demais membros da família nos atendimentos aos adolescentes ofensores sexuais. Foram várias as falas que ilustraram e identificaram a ocorrência de mudanças nas relaçôes familiares, mesmo quando as mães reconheceram a participação no GM como difícil e também o quanto era sofrido encararem a discussão sobre esta temática. Nota-se a ausência de informaçôes dadas pelos pais em função de que o instrumento foi respondido unicamente pelas mães. Esse dado é recorrente e ilustra a maior aproximação do filho adolescente com a mãe e um lugar mais periférico do pai em relação aos conflitos do adolescente. Apesar de terem comparecido ao GM um pai, um tio e um padrasto, a figura da mãe sobressai em todos os momentos, corroborando as observaçôes de Penso e Sudbrack (2004) de que esses adolescentes (infratores) permanecem parentalizados com a mãe e afastados afetivamente do pai.

Ressalta-se, ainda, que o atendimento em grupo oferece sim recursos para mudanças, como vários autores enfatizam e preconizam: Costa et al. (2009); Henggeler et al. (1992); Timmons-Mitchell et al. (2006). A discussão da temática em 
comum facilita o enfrentamento de uma situação na qual os sofrimentos também são percebidos como comuns a todos. As dificuldades de estar em grupo estão ligadas à vergonha e à tentativa de calar sobre o fato e a vergonha. Neste sentido, estar em grupo é um desafio e uma estratégia para que a família possa questionar e conversar de forma mais clara sobre encobrir a verdade e postergar mudanças.

E, finalmente, sugere-se que a intervenção em grupo, que atende aos membros da família e aos adolescentes, contempla a dimensão do sofrimento de todos e favorece a aproximação afetiva, a distensão do clima de acusação e punição ao adolescente, além de atenuar a vergonha e o isolamento da família e do adolescente. Estas condições são apontadas por Timmons-Mitchell et al. (2006) como um trabalho de prevenção que abrange a família, o adolescente e possíveis vítimas.

\section{REFERÊNCIAS}

Almeida, T. M. C., Penso, M. A., \& Costa, L. F. (2009). Abuso sexual infantil masculino: o gênero configura o sofrimento e o destino? Estilos da Clínica, XIV (26), 46-67.

Borduin, C. M., Schaeffer, C. M., \& Heiblum, N. (2009). A randomized clinical trial of multisystemic therapy with juvenile sexual offenders: effects on youth social ecology and criminal activity. Journal of Consulting and Clinical Psychology, 77 (1), 26-37.

Costa, L. F., \& Santos, V. A. (2004). Família e violência sexual contra crianças: o papel da justiça na construção e reconstrução de significados. Psicologia. Teoria, investigaçãa eprática, 9 (1), 47-63.

Costa, L. F., Penso, M. A., \& Almeida, T. (2005). O grupo multifamiliar: um método de intervenção em situações de abuso sexual infantil. Psicologia USP, 16 (4), 121-146.

Costa, L. F., Penso, M. A., Almeida, T. M. C. de, \& Ribeiro, M. A. (2008). "A justiça é demorosa, burra e cega”. Percepçōes de famílias sobre a dimensão jurídica dos crimes de abuso sexual. Boletim de Psicologia, LVIII (128), 85-102.

Costa, L. F., Almeida, T. M. C., Ribeiro, M. A., \& Penso, M. A. (2009). Grupo Multifamiliar: espaço para a escuta das famílias em situação de abuso sexual. Psicologia em Estudo, Maringá, 14 (1), 21-30.

Costa, L. F., \& Lima, C. M. (2010). Abuso sexual infanto-juvenil: da proteção à culpa e ruptura. Nova Perspectiva Sistêmica, XIX (36), 87-102.

Costa, L. F., Penso, M. A., Almeida, T. M. C. de, Ribeiro, M. A., \& Nogueira, H. F. (2010). O Grupo Multifamiliar em parceria com a ação psicossocial forense. Psicologia em Interação, 14 (1), 73-82.

Estatuto da Criança e do Adolescente (1990). Lei no 8069/90.

Furniss, T. (1993). Abuso sexual da criança. Uma abordagem multidisciplinar. Porto Alegre: 
Artes Médicas.

Gaulejac, V. (2006). As origens da vergonha. São Paulo: Via Lettera.

Gonçalves, H. S., \& Ferreira, A. L. (2002). A notificação da violência intrafamiliar contra crianças e adolescentes por profissionais de saúde. Cadernos de Saúde Pública, 18 (1), 315-319.

Gonçalves, C. S., Wolff, J. R., \& Almeida, W. C. (1988). Lições de psicodrama. São Paulo: Ágora.

González Rey, F. (2005). Pesquisa qualitativa e subjetividade. Os processos de construção da informação. São Paulo: Thomson.

Headman, N. C., \& Cornille, T. A. (2008). Family functioning patterns as predictors of engagement: which families participate in services and which ones do not? Journal of Family Social Work, 11 (2), 117-140.

Henggeler, S. W., Melton, G. B., \& Smith, L. A. (1992). Family preservation using multisystemic therapy: an effective alternative to incarcerating serious juvenile offenders. Journal of Consulting and Clinical Psychology, 60, 953-961.

Henggeler, S. W., Letourneau, E. J., Chapman, J. E., Borduin, C. M., Schewe, P. A., \& McCart, M. R. (2009). Mediators of change for multisystemic therapy with juvenile sexual offenders. Journal of Consulting and Clinical Psychology, 77, 3, 451-462.

Hirsch, H. (1998). Efectividad en psicoterapia. Sistemas familiares, 14 (3), 85-97.

Hooper, C.-A. (1994). Madres sobrevivientes al abuso sexual de sus niños. Buenos Aires: Nueva Visión.

Lane, S. T. M., \& Sawaia, B. B. (1995). La Psicología Social Comunitaria en Brasil. In: Wiesenfeld, E. y Sánchez, E. (comp.). Psicología Social Comunitaria. Contribuiciones Latinoamericanas (pp. 69-112). Caracas: Fondo Editorial Tropykos.

Laquer, P. (1983). Terapia familiar múltipla: perguntas e respostas. In: Bloch, D. (coord.). Técnicas de psicoterapia familiar (pp. 93-107). São Paulo: Atheneu.

McGoldrick, M., \& Gerson, R. (1995). Genetogramas e o ciclo de vida familiar. In: Carter, B., \& McGoldrick, M. (orgs.). As mudanças no ciclo de vida vamiliar (pp. 144-166). Porto alegre: Artes Médicas.

Minuchin, S. (1982). Famílias. Funcionamento \& tratamento. Porto Alegre: Artes Médicas.

Minuchin, P., Colapinto, J., \& Minuchin, S. (1999). Trabalhando com famílias pobres. Porto Alegre: Artes Médicas.

Miller, D. (1994). Incesto: o centro da escuridão. In: Imber-Black, E. e colaboradores. Os Segredos na família e na terapia familiar (pp. 185-199). Porto Alegre: Artes Médicas.

Moreno, J. L. (1993). Psicoterapia de grupo e psicodrama. Campinas: Psy.

Oliver, B. E. (2007). Three steps to reducing child molestation by adolescents. Child Abuse \& Neglect, 31, 683-689. 
Penso, M. A., \& Sudbrack, M. F. O. (2004). Envolvimento em atos infracionais e com drogas como possibilidade para lidar com o papel do filho parental. Psicologia USP, 15 (3) $29-54$.

Sanderson, C. (2005). Abuso sexual em crianças. São Paulo: M. Books

Santos, B. S. (1999). Um discurso sobre as ciências. Porto: Afrontamento.

Sluzki, C. E. (1996). Violência familiar e violência política: implicações terapêuticas de um modelo geral. In: Schnitman, D. F. (org.). Novos paradigmas, cultura e subjetividade (pp. 228-243). Porto Alegre: Artes Médicas.

Sinclair, C., \& Martínez, J. (2006). Culpa o responsabilidad: terapia con madres de niñas y niños que han sufrido abuso sexual. Psyche, 15 (2), 25-35.

Timmons-Mitchell, J., Bender, M. B., Kishna, M. A., \& Mitchell, C. C. (2006). An independent effectiveness trial of multisystemic therapy with justice youth. Journal of Clinical Child and Adolescent Psychology, 35 (2), 227-236.

Vizir, P., Bringiotti, M. I., Peroni, G., Nyman, A., Tablado, A., Label, H. P., \& Crescini, S. (2004). Abuso sexual infantil. Sistemas familiares y otros sistemas humanos, 20, 119132.

Recebido em 10 de julho de 2010 Aceito para publicação em 30 de março de 2011

\section{Anexo}

Quadro 1 - Informações sobre as famílias e os respondentes

\begin{tabular}{|c|c|c|c|c|c|}
\hline & Família - papéis e idades & $\begin{array}{c}\text { Quem } \\
\text { compareceu ao } \\
\text { GM }\end{array}$ & $\begin{array}{c}\text { Quem } \\
\text { respondeu ao } \\
\text { instrumento }\end{array}$ & $\begin{array}{l}\text { Ofensor } \\
\text { sexual }\end{array}$ & A vítima \\
\hline Família Alê & $\begin{array}{l}\text { mãe } 43 \text { a, padrasto } 34 \mathrm{a}, \\
\text { filha } 16 \mathrm{a} \text {, adolescente } 15 \mathrm{a} \text {, } \\
\text { filha } 10 \mathrm{a}\end{array}$ & $\begin{array}{l}\text { mãe, irmã, adoles- } \\
\text { cente }\end{array}$ & mãe & $\begin{array}{l}\text { adolescente } \\
15 \mathrm{a}\end{array}$ & irmã $10 \mathrm{a}$ \\
\hline Família Edu & $\begin{array}{l}\text { pai } 58 \text { a, mãe } 44 \text { a, irmã } 29 \\
\text { a, irmão } 28 \text { a, irmão } 27 \text { a, } \\
\text { irmã } 8 \text { a, adolescente } 17 \text { a }\end{array}$ & mãe, adolescente & mãe & $\begin{array}{l}\text { adolescente } \\
17 \mathrm{a}\end{array}$ & $\begin{array}{l}\text { sobrinha } \\
12 \mathrm{a}\end{array}$ \\
\hline Família Apê & $\begin{array}{l}\text { pai } 48 \text { a, mãe } 48 \text { a, irmã } 4 \\
\text { a, adolescente } 15 \text { a }\end{array}$ & $\begin{array}{l}\text { mãe, pai, irmã, } \\
\text { adolescente }\end{array}$ & mãe & $\begin{array}{l}\text { adolescente } \\
15 \mathrm{a}\end{array}$ & irmã 4 a \\
\hline Família Wal & $\begin{array}{l}\text { mãe } 51 \text { a, irmão } 27 \text { a, } \\
\text { adolescente } 17 \text { a } \\
\text { (avó } 81 \text { a, avô } 77 \text { a, tia } 43 \\
\text { a, tia } 51 \text { a, primo } 5 \text { a - mo- } \\
\text { ram no mesmo terreno) }\end{array}$ & $\begin{array}{l}\text { mãe, adolescente, } \\
\text { avó, tia, tio }\end{array}$ & mãe & $\begin{array}{l}\text { adolescente } \\
17 \mathrm{a}\end{array}$ & primo $5 \mathrm{a}$ \\
\hline
\end{tabular}




\begin{tabular}{|c|c|c|c|c|c|}
\hline & Família - papéis e idades & $\begin{array}{c}\text { Quem } \\
\text { compareceu ao } \\
\text { GM }\end{array}$ & \begin{tabular}{|c|} 
Quem \\
respondeu ao \\
instrumento \\
\end{tabular} & $\begin{array}{c}\text { Ofensor } \\
\text { sexual }\end{array}$ & A vítima \\
\hline Família Jô & $\begin{array}{l}\text { mãe } 35 \text { a, padrasto } 42 \text { a, } \\
\text { adolescente } 17 \text { a, irmã } 13 \text { a, } \\
\text { prima } 7 \text { a }\end{array}$ & mãe, adolescente & mãe & $\begin{array}{l}\text { adolescente } \\
17 \mathrm{a}\end{array}$ & irmã 7 a \\
\hline Família Tom & $\begin{array}{l}\text { mãe } 33 \text { a, padrasto } 33 \text { a, } \\
\text { meia irmã } 7 \text { a, adolescente } \\
14 \text { a }\end{array}$ & $\begin{array}{l}\text { mãe, adolescen- } \\
\text { te, avó, irmã, } \\
\text { padrasto }\end{array}$ & mãe & $\begin{array}{l}\text { adolescente } \\
14 \mathrm{a}\end{array}$ & $\begin{array}{l}\text { meia irmã } \\
7 \text { a, filha } \\
\text { padrasto }\end{array}$ \\
\hline Família Go & $\begin{array}{l}\text { mãe } 34 \text { a, adolescente } 14 \text { a, } \\
\text { irmão } 10 \text { a, irmã } 11 \text { a, irmã } \\
04 \text { a, irmã } 03 \text { a. }\end{array}$ & mãe, adolescente & mãe & $\begin{array}{l}\text { adolescente } \\
14 \mathrm{a}\end{array}$ & irmã 04 a \\
\hline
\end{tabular}

